\title{
Fatty acid amide hydrolase deficiency limits early pregnancy events
}

\author{
Haibin Wang, ${ }^{1}$ Huirong Xie, ${ }^{1}$ Yong Guo, ${ }^{1}$ Hao Zhang, ${ }^{1}$ Toshifumi Takahashi, ${ }^{1}$ Philip J. Kingsley,, \\ Lawrence J. Marnett, 2 Sanjoy K. Das, ${ }^{1,3}$ Benjamin F. Cravatt, ${ }^{4}$ and Sudhansu K. Dey1,5,6
}

\begin{abstract}
1Department of Pediatrics, ${ }^{2}$ Department of Biochemistry, Institute of Chemical Biology, and ${ }^{3}$ Department of Cancer Biology, Vanderbilt University Medical Center, Nashville, Tennessee, USA. ${ }^{4}$ The Scripps Research Institute, La Jolla, California, USA. ${ }^{5}$ Department of Cell and Developmental Biology and ${ }^{6}$ Department of Pharmacology, Vanderbilt University Medical Center, Nashville, Tennessee, USA.
\end{abstract}

\begin{abstract}
Synchronized preimplantation embryo development and passage through the oviduct into the uterus are prerequisites for implantation, dysregulation of which often leads to pregnancy failure in women. Cannabinoid/ endocannabinoid signaling via cannabinoid receptor $\mathrm{CB} 1$ is known to influence early pregnancy. Here we provide evidence that a critical balance between anandamide synthesis by $N$-acylphosphatidylethanolamine-selective phospholipase D (NAPE-PLD) and its degradation by fatty acid amide hydrolase (FAAH) in mouse embryos and oviducts creates locally an appropriate "anandamide tone" for normal development of embryos and their oviductal transport. FAAH inactivation yielding higher anandamide or experimentally induced higher cannabinoid [(-)- $\Delta^{9}$-tetrahydrocannabinol] levels constrain preimplantation embryo development with aberrant expression of Cdx2, Nanog, and Oct3/4, genes known to direct lineage specification. Defective oviductal embryo transport arising from aberrant endocannabinoid signaling also led to deferred on-time implantation and poor pregnancy outcome. Intercrossing between wild-type and $\mathrm{Faab}^{-/-}$mice rescued developmental defects, not oviductal transport, implying that embryonic and maternal FAAH plays differential roles in these processes. The results suggest that FAAH is a key metabolic gatekeeper, regulating on-site anandamide tone to direct preimplantation events that determine the fate of pregnancy. This study uncovers what we believe to be a novel regulation of preimplantation processes, which could be clinically relevant for fertility regulation in women.
\end{abstract}

\section{Introduction}

Preimplantation embryo development consists of successive cleavage of the fertilized egg, leading to the formation of a morula, which undergoes compaction before differentiation to a blastocyst with cavitation. Another critical event that occurs in parallel is the timely transport of embryos from the oviduct into the uterus. In mice, embryos at the late morula or early blastocyst stage enter the uterus, where they develop and differentiate to achieve implantation competency, escape from zonae pellucidae, and implant into receptive uteri. Thus, normal oviductal embryo transport is prerequisite for on-time implantation. Oviductal embryo retention resulting from a dysfunctional regulation of the process may lead to tubal pregnancy or pregnancy failure in women (1). An emerging concept in embryo development and implantation is the role of anandamide ( $\mathrm{N}$-arachidonoylethanolamine [AEA]), an endogenously produced cannabinoid-like lipid mediator termed endocannabinoid (2-4). It binds to and activates 2 classical $G$ protein (Gi/o)-coupled cell-surface cannabinoid receptors, cannabinoid receptor type 1 (CB1) and $\mathrm{CB} 2(5,6)$. Our previous studies have established in mice that both preimplantation mouse embryos and oviducts are targets of cannabinoid/endocannabinoid signaling $(7,8)$. This signaling could be dependent on the status of cannabinoid receptors or ligands. We have previously shown that intervention of normal CB1 function leads to defective develop-

Nonstandard abbreviations used: BW, body weight; CB1, cannabinoid receptor type 1 ; CBD, cannabidiol; CBN, cannabinol; FAAH, fatty acid amide hydrolase; ICM, inner cell mass; NAPE, $N$-acylphosphatidylethanolamine; NAPE-PLD, NAPE-selective phospholipase D; THC, (-)- $\Delta^{9}$-tetrahydrocannabinol; Tr, trophectoderm.

Conflict of interest: The authors have declared that no conflict of interest exists.

Citation for this article: J. Clin. Invest. 116:2122-2131 (2006). doi:10.1172/JCI28621. ment of preimplantation embryos and their oviductal transport, leading to compromised pregnancy outcome $(8,9)$. We also showed that while anandamide at low levels induces blastocyst activation by activating MAPK signaling, it at higher levels inhibits blastocyst activation for implantation by blocking $\mathrm{Ca}^{2+}$ signaling via CB1 (10). These findings led us to speculate that under normal physiological settings, a basal "anandamide tone" imparts an appropriate CB1 function that is crucial to early pregnancy events. However, whether this anandamide tone is present and critical to these events in vivo and, if so, the underlying mechanism by which this tone is established in a tissue and region-specific manner during early pregnancy remain unknown.

Anandamide biosynthesis primarily results from hydrolysis of a phospholipid precursor, $N$-acylphosphatidylethanolamine (NAPE), in the cell membrane by a NAPE-selective phospholipase D (NAPEPLD), while its degradation is catalyzed by fatty acid amide hydrolase (FAAH) (11). The cloning of Nape-pld and Faah, which encode these enzymes $(12,13)$, respectively, has opened a way to study anandamide biosynthesis and degradation in vivo. We surmised that these 2 key steps regulate anandamide levels during early pregnancy. Indeed, our results showing coordinated expression of NAPE-PLD and FAAH in the mouse oviduct and preimplantation embryos suggest that there is a physiological anandamide tone for normal development of preimplantation embryos and their timely homing into uterus for implantation. Our genetic and pharmacological studies provide strong evidence that FAAH is a major player in these events.

\section{Results}

Exposure to (-)- $\Delta^{9}$-tetrabydrocannabinol causes retarded development and oviductal retention of embryos. We previously observed that an exaggerated CB1 signaling by methanandamide, an anandamide ana- 
A

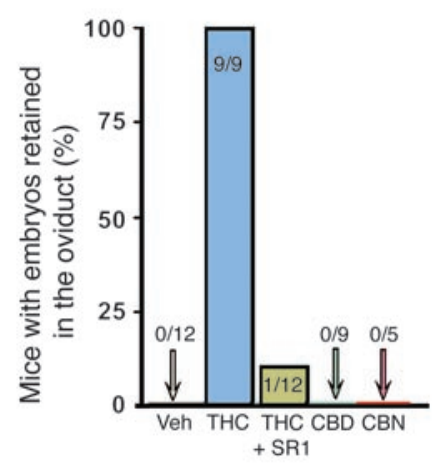

D

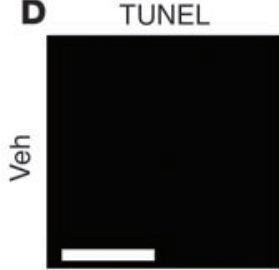

Nuclei

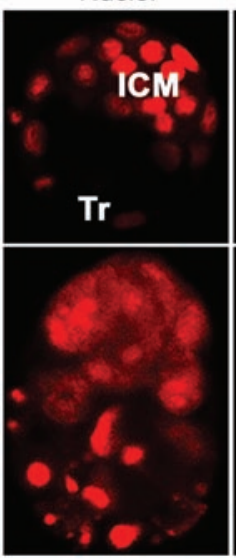

B

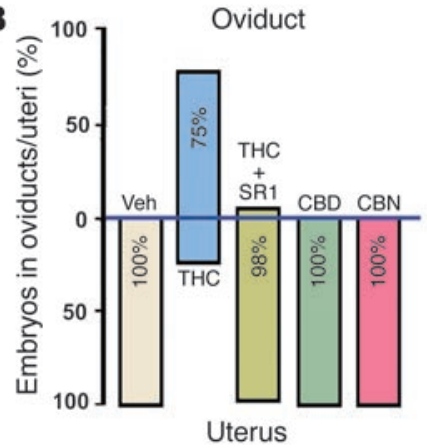

E
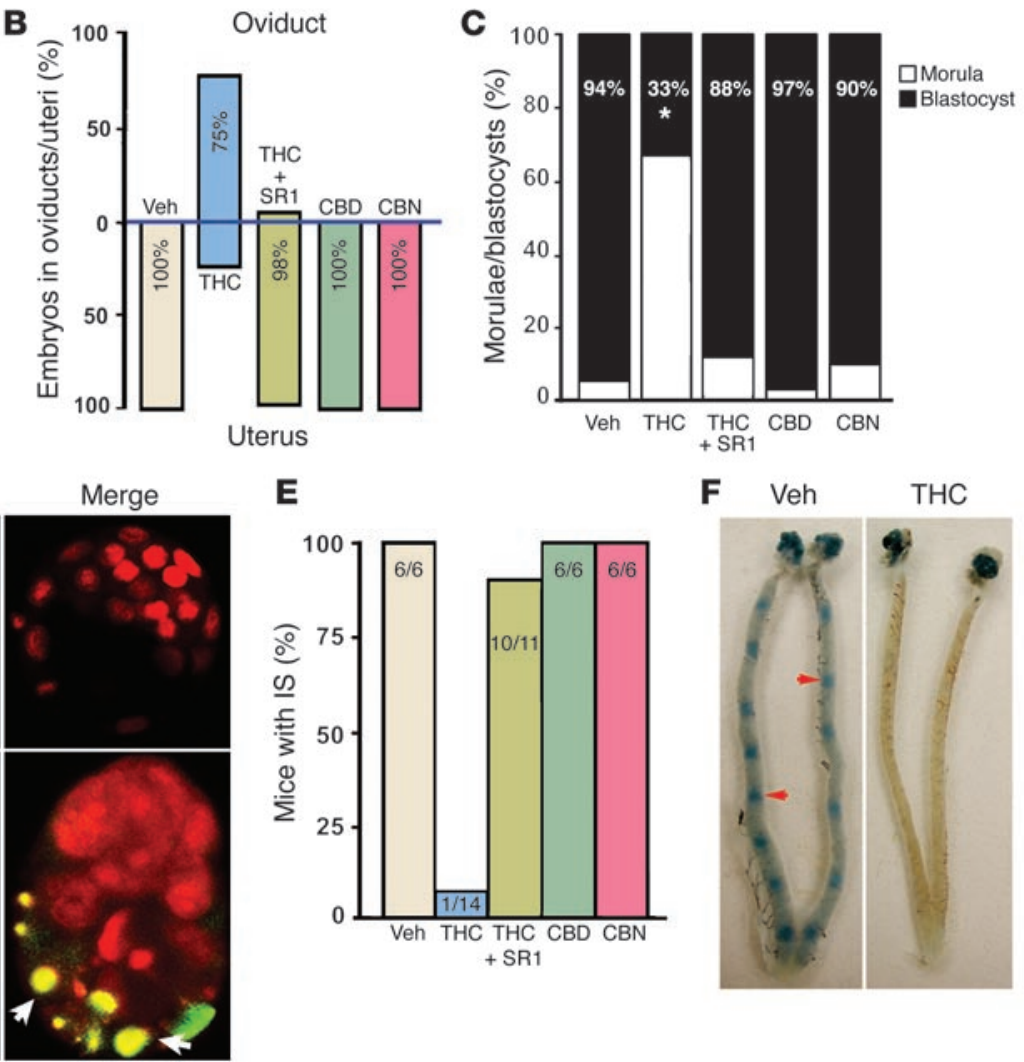

F Veh THC

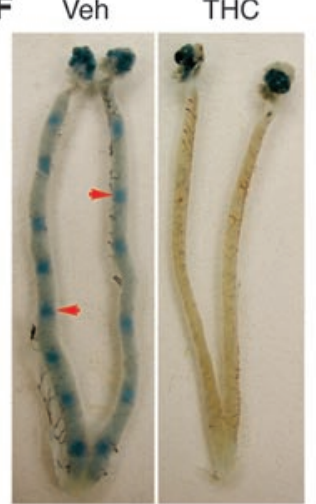

Figure 1

Impact of marijuana exposure on oviductal transport, early embryo development, and implantation in wild-type mice. (A) Number of mice with oviductal embryo retention per total number of mice examined on day 4 of pregnancy. (B) Percentage of embryos recovered from oviducts or uteri. (C) Differential distribution of morulae and blastocysts among drug-treated groups. Statistical significance between treatment groups was evaluated using unpaired 1-tailed Student's $t$ test $\left({ }^{*} P<0.01\right)$. (D) TUNEL analysis in blastocysts upon maternal exposure to THC in vivo. Images shown depict FITC-labeled apoptotic cells as green, propidium iodide-labeled nuclei as red, and merge as yellow (scale bar: $20 \mu \mathrm{m})$. (E and F) Implantation in mice receiving different drug treatments. Implantation sites (IS) were visualized by the blue-dye method on day 5 mid-morning. Numbers within the bars in $\mathbf{E}$ indicate the number of mice with implantation sites per total number of mice examined. The results show that while THC, the most psychoactive component of marijuana, but not the inactive CBD and CBN, derails oviductal embryo transport, retards preimplantation embryo development, induces apoptosis in blastocysts, and blocks implantation in wild-type mice, SR141716 (SR1, a selective CB1 antagonist) largely reduces the detrimental effects of THC exposure. Veh, vehicle.

log, disrupts normal development and oviductal journey of preimplantation embryos (8). Since marijuana is still one of the most widely used illicit drugs in the world $(14,15)$, and often by pregnant women (16), we explored the pathophysiological relevance of exposure to herbal cannabinoids during early pregnancy in mice. We tested the effects of (-)- $\Delta^{9}$-tetrahydrocannabinol (THC), cannabidiol (CBD), or cannabinol (CBN) on preimplantation embryo development and implantation in wild-type mice. These compounds were chosen since THC is the primary psychoactive component of marijuana (17) that elicits cannabinoid signaling primarily via cannabinoid receptors, while CBD (the biosynthetic precursor of THC) and CBN (an oxidation product of THC) are considered nonpsychoactive cannabinoids and have low affinity for CB1 (18-20). Pregnant females were continuously infused with the specific drugs via miniosmotic pumps from day 1 of pregnancy until sacrificed. The daily dose of each drug was $5 \mathrm{mg} / \mathrm{kg}$ body weight (BW). As shown in Figure 1, when examined mid-morning of day 4, all of the mice treated with THC showed oviductal retention of embryos with asynchronous development, while none of the mice treated with either vehicle, $\mathrm{CBD}$, or $\mathrm{CBN}$ showed these effects (Figure 1, A-C). Embryos recovered from mice receiving THC treatment also showed signs of apoptosis (Figure 1D). We speculated that these developmentally retarded embryos eventually fail to implant in the uterus. Thus, we next examined implantation in the wild-type mice receiving THC, CBD, or CBN on days 1-4. An increased localized endometrial vascular permeability at the site of the blastocyst is one of the early markers of implantation (21) and can be monitored by an intravenous injection of a blue dye (Chicago blue B) solution, which specifies implantation sites as distinct blue bands along the uterus $(21,22)$. When examined on day 5 , most of the mice ( 7 of 8 ) exposed to THC failed to show any sign of implantation (blue bands) with recovery of unimplanted blastocysts, whereas mice treated with vehicle, CBD, or CBN showed normal implantation (Figure 1, E and F). The adverse effects of THC on these events were markedly improved by administration of SR141716, a selective CB1 antagonist, with THC (Figure 1, A-C and $\mathrm{E}$ ), suggesting that the detrimental effects of THC are largely mediated via CB1. These findings reinforce the idea that during normal pregnancy, locally produced endocannabinoids elicit an "endocannabinoid tone" conducive to synchronous development 
A

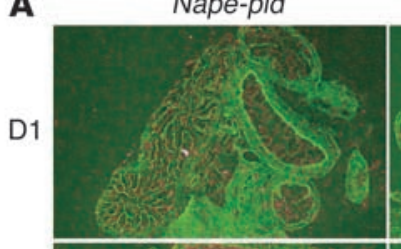

Nape-pld

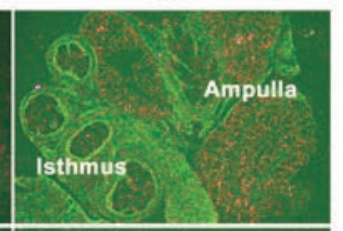

$\mathrm{D} 2$
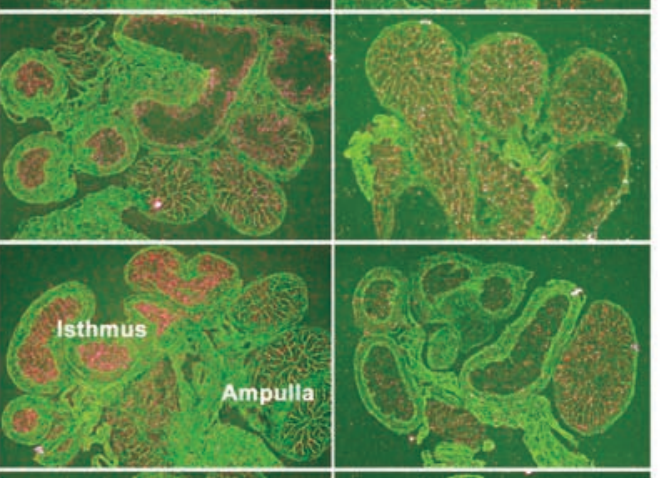

D4
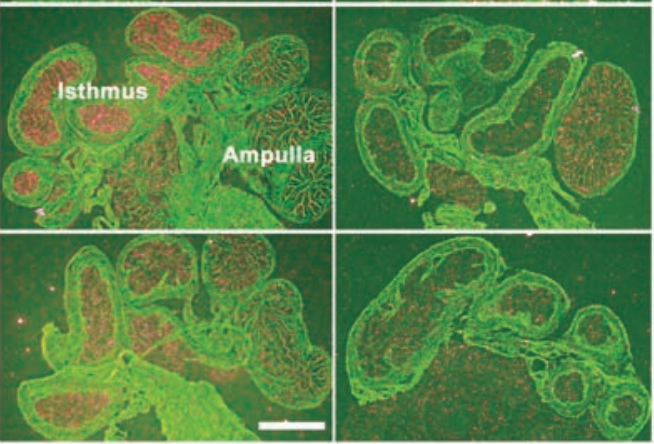

B

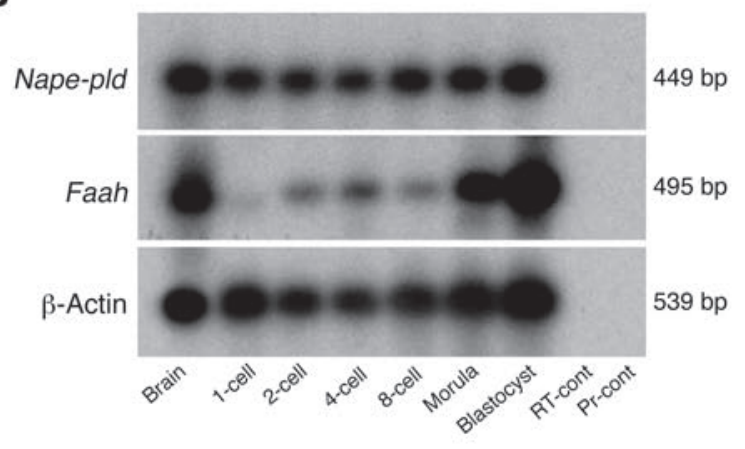

C

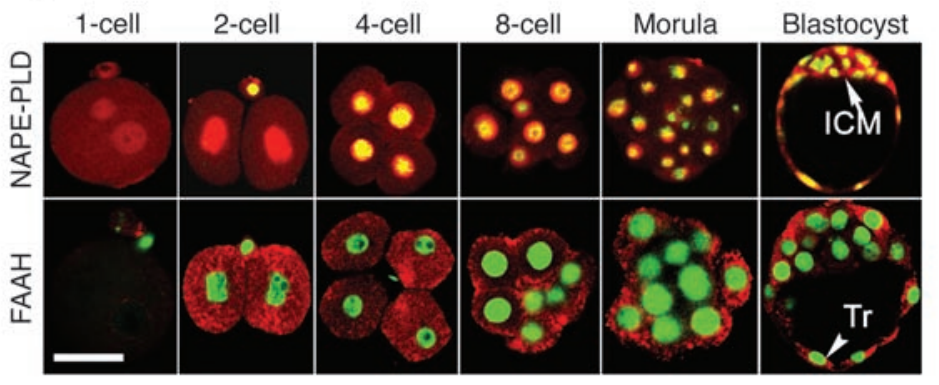

Figure 2

Expression of Nape-pld and Faah in the oviduct and preimplantation embryos. (A) Spatiotemporal expression profiles of Nape-pld and Faah mRNA in the oviduct on days 1-4 (D1-4) of pregnancy. The results show that Nape-pld and Faah are expressed in a cell- and region-specific manner in the mouse oviduct during the preimplantation period. Higher levels of Nape-pld were detected in the oviduct epithelium at the isthmus region but much lower levels in the ampullary region. In contrast, Faah was primarily expressed in the epithelium at the ampullary region, with lower expression in the isthmus. Scale bar: $25 \mu \mathrm{m}$. (B and C) Cell-specific expression of Nape-pld and Faah mRNA and protein expression in preimplantation embryos. The results show that NAPE-PLD and FAAH are differentially expressed in the preimplantation embryos. While NAPEPLD was expressed at all stages of preimplantation embryos, from fertilized 1-cell embryos to blastocysts, FAAH was expressed upon activation of the embryonic genome at the 2-cell stage and beyond. NAPE-PLD protein was detected in both nuclei and cytoplasm by this commercially available antibody. FAAH protein was detected in the cytoplasm and was primarily localized to outside cells in morulae and blastocysts. Images depict TRITC-labeled antigens as red, SYTO-13-labeled nuclei as green, and merge as yellow (scale bar: 50 um). RT-cont, RNA without RT reaction; Pr-cont, primer control.

and timely journey of embryos through the oviduct for on-time implantation, whereas an exposure to exogenous cannabinoid ligands such as THC swamps this endocannabinoid tone, leading to early pregnancy failure.

NAPE-PLD and FAAH are expressed in a spatiotemporal manner in oviducts on days 1-4 of pregnancy. If regulated anandamide signaling is critical to normal development of embryos and their oviductal transport, it is important to know how appropriate levels of anandamide are locally produced. We performed in situ hybridization experiments to examine Nape-pld and Faab expression in the oviduct during early pregnancy. As shown in Figure 2A, we observed an interesting expression pattern. In general, higher levels of Nape-pld expression were detected in the oviduct epithelium at the isthmus region as compared with much lower levels in the ampullary region. In contrast, Faab was expressed at higher levels in the epithelium at the ampullary region, with lower levels in the isthmus. This regionspecific inverse expression profile of Nape-pld and Faab suggests that a spatiotemporal coordination of anandamide synthesis and degradation is conducive to preimplantation embryo development and timely transport of developing embryos in the oviduct.

NAPE-PLD and FAAH are expressed in preimplantation embryos. To explore the embryonic contribution to regulating anandamide levels during early pregnancy, we performed RT-PCR followed by Southern hybridization to examine Nape-pld and Faab expression in preimplantation embryos. As shown in Figure 2B, Nape-pld was expressed in embryos at all stages, from fertilized 1-cell embryos to blastocysts, whereas Faah was first detected in 2-cell embryos with the onset of embryonic genome activation, and its expression was dramatically upregulated at the morula and blastocyst stages. These observations indicate that preimplantation embryos also have the machinery to synthesize and hydrolyze anandamide in a developmental stage-specific manner.

Using immunofluorescence, we further observed that preimplantation embryos at all stages expressed NAPE-PLD, whereas FAAH protein was expressed in embryos beyond the 2-cell stage (Figure 2C); this is consistent with their mRNA expression. Interestingly, NAPE-PLD was localized in both the cytoplasm and nucleus, although the significance of nuclear localization of NAPE-PLD in preimplantation embryos is not clear at this time. It is worth noting that FAAH is mostly expressed in outer cells of morulae and the trophectoderm (Tr) of blastocysts. Since lower anandamide levels are beneficial for blastocyst differentiation and implantation as opposed to higher levels, which are detrimental to these processes $(10,23)$, the observation of increasing and 

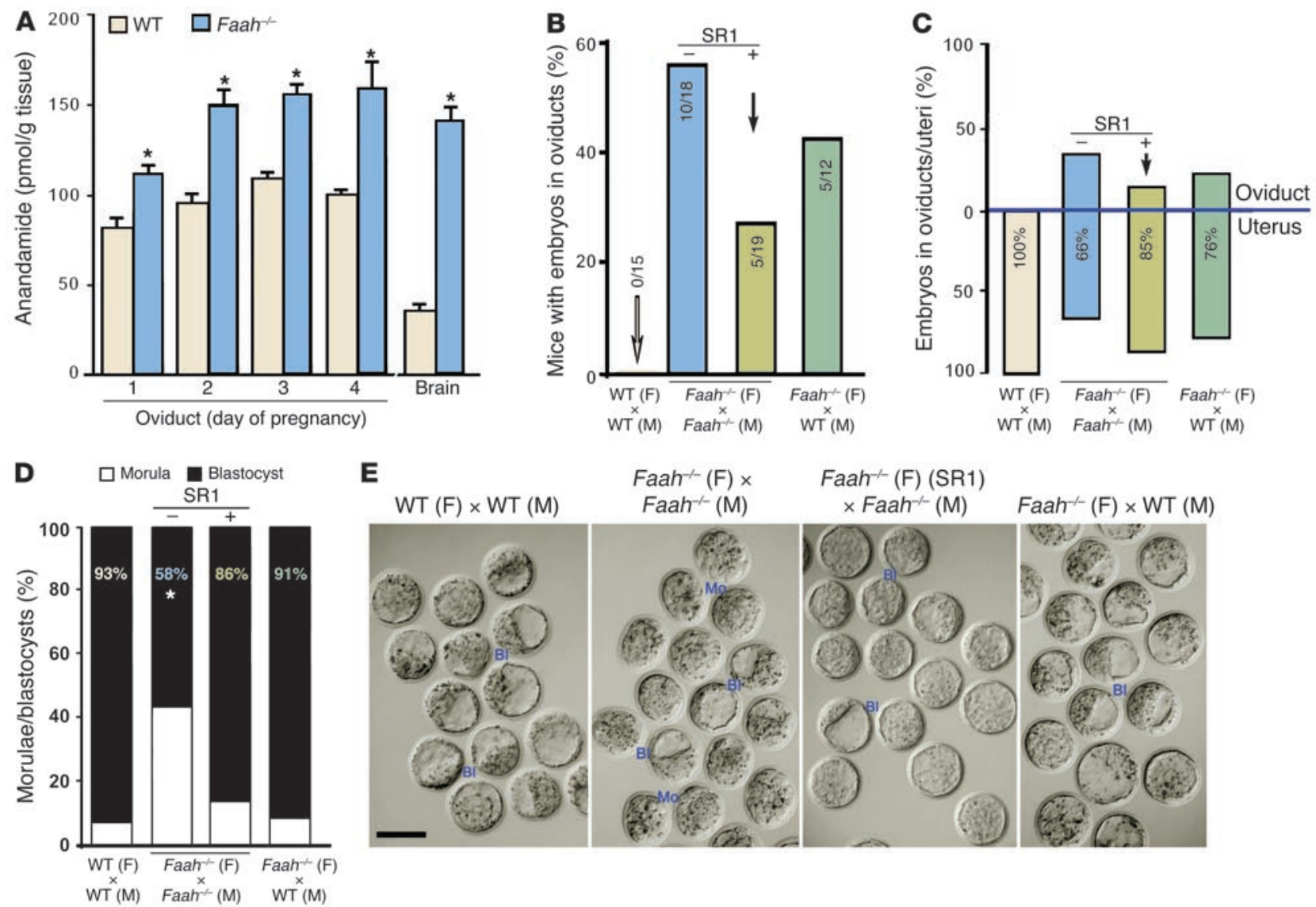

$\mathrm{Faah}^{-\alpha}(\mathrm{F}) \times \mathrm{WT}(\mathrm{M})$

Figure 3

FAAH deficiency increases oviductal anandamide levels, leading to tubal retention and retarded embryo development in mice. (A) Oviductal levels of anandamide were significantly increased in Faah ${ }^{-1-}$ mice during early pregnancy. (B) Number of mice with oviductal embryo retention per total number of mice examined on day 4 of pregnancy. (C) Percentage of embryos recovered from oviducts or uteri. (D and E) Asynchronous development of embryos in Faah ${ }^{-/}$mice. The results show that higher levels of oviductal anandamide are correlated with oviductal retention of embryos and retarded embryo development in Faah ${ }^{-/-}$mice. Statistical analysis was performed using unpaired 1-tailed Student's $t$ test $\left({ }^{\star} P<0.05\right)$. Scale bar: $100 \mu \mathrm{m}$. Mo, morula; Bl, blastocyst; M, male; F, female.

localized expression of FAAH in morulae and blastocysts suggests that FAAH-mediated anandamide degradation functions as a protective mechanism against any deleterious effects from excessive anandamide production.

FAAH deficiency elevates anandamide levels in oviducts during early pregnancy. To provide genetic evidence regarding FAAH's function in early pregnancy, we measured anandamide levels in both wild-type and $\mathrm{Faah}^{-/-}$mouse oviducts ( $n=3-6$; each assay included oviducts pooled from 10-15 mice) on days 1-4 of pregnancy using reversephase positive-ion electrospray ionization/high-performance liquid chromatography/tandem mass spectrometry (ESI-HPLC-MS-MS) assay as previously described $(8,24)$. As shown in Figure 3A, an overall significantly increased oviductal anandamide level was observed in the absence of FAAH, suggesting that FAAH is indeed one of the primary enzymes that regulates anandamide turnover. It was also interesting to note that the oviduct contains much higher levels of anandamide than the brain, reinforcing the idea that anandamide signaling is important during early pregnancy.

FAAH deficiency or inhibition derails oviductal embryo transport. Since aberrant cannabinoid signaling impairs oviductal embryo transport, observation of increased oviductal anandamide levels in the absence of FAAH led us to examine the consequence of FAAH deficiency on timely journey of embryos from oviducts into uteri. When examined on day 4 mid-morning, a considerable number (10 of 18) of $\mathrm{Faah}^{-/-}$mice showed oviductal retention of embryos, as opposed to none of the wild-type mice (Figure 3, B and C). Moreover, when pregnant wild-type females were treated with a selective FAAH inhibitor, URB597 (cyclohexyl carbamic acid 3 '-carbamoyl-biphenyl-3-yl ester) (25), at a daily dose of $1 \mathrm{mg} / \mathrm{kg}$ BW on days $1-3,75 \%$ of them (9 of 12) showed oviductal retention of embryos when examined on day 4 mid-morning (Figure 4, $\mathrm{B}$ and $\mathrm{C}$ ). This impaired oviductal embryo transport in wild-type females is apparently due to substantially increased anandamide levels upon FAAH inhibition (Figure 4A). These findings provide genetic and pharmacological evidence that FAAH is at least one of the determinants for creating appropriate levels of anandamide conducive to normal embryo passage from the oviduct into the uterus during early pregnancy. In addition, we also observed that an enhanced anandamide signaling by genetic ablation of FAAH or its pharmacological inhibition leads to asynchronous early embryo development in vivo (Figure 3, D and E, and Figure 4D), supporting the hypothesis that regulated anandamide signaling is critical to normal preimplantation development. It is interesting to note that the normal development of embryos, but not their defective ovi- 
A

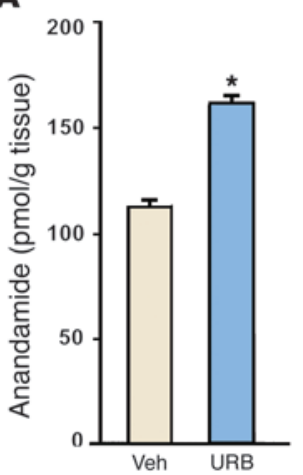

B

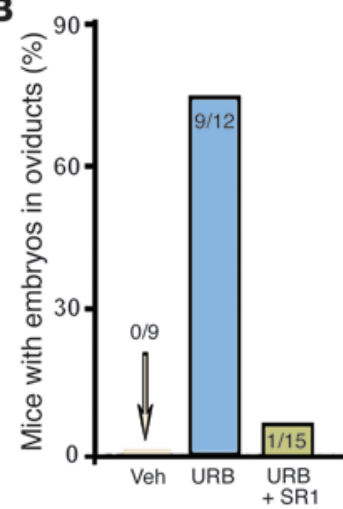

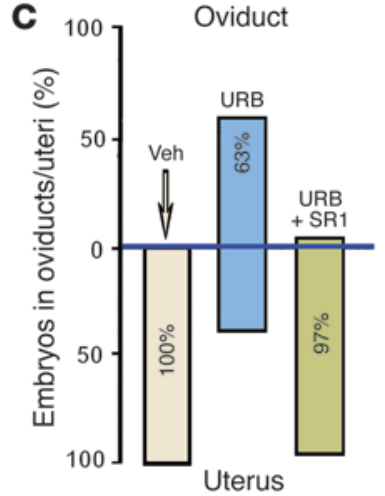

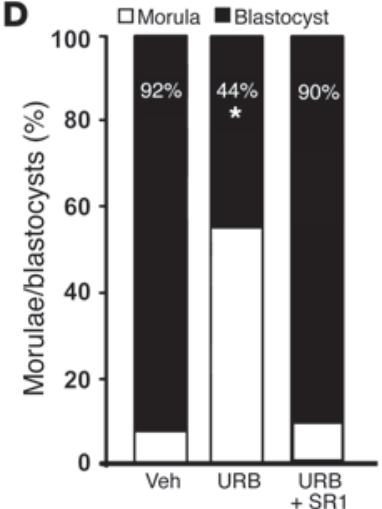

Figure 4

Elevated anandamide signaling by pharmacological inhibition of FAAH causes impaired oviductal embryo transport in wild-type mice. (A) FAAH inhibition by its selective inhibitor URB597 (URB) increased oviductal levels of anandamide in pregnant wild-type females. Pregnant wild-type females received subcutaneous injection of URB597 at a dose of $1 \mathrm{mg} / \mathrm{kg}$ BW on days 1-3, and oviductal tissues were collected after treated females were sacrificed 3 hours after the last drug administration. (B) Number of mice with embryos retained in the oviduct per total number of mice examined. (C) Percentage of embryos recovered from oviducts or uteri of mice with different treatments. (D) Differential distribution of morulae and blastocysts among the drug-treated groups. Oviductal retention of embryos with impaired growth was noted in wild-type mice via silencing of FAAH activity by the selective inhibitor URB597, which was substantially restored when mice were cotreated with URB597 and SR141716. Statistical significance between treatment groups was evaluated using unpaired 1-tailed Student's $t$ test $\left({ }^{\star} P<0.05\right)$.

ductal transport, was restored by mating $\mathrm{Faah}^{-/-}$females with wildtype males, generating all heterozygous embryos (Figure 3, B-E). Moreover, the adverse effects of genetic or pharmacological interference of FAAH function were substantially improved after CB1 function was attenuated by SR141716 (Figure 3, B-E, and Figure 4, B-D). These results suggest that impaired preimplantation events arising from FAAH silencing were primarily the result of enhanced anandamide/CB1 signaling but apparently not due to other FAAHhydrolysable amides, including oleamide, palmitoylethanolamide, and oleoylethanolamide (26). Collectively, the results suggest that FAAH plays a critical role in regulating appropriate anandamide levels for normal development of embryos and their oviductal transport. Since successful implantation absolutely depends on synchronous development of embryos to the blastocyst stage prior to implantation, our next objective was to examine the developmental status of preimplantation embryos in $\mathrm{Faah}^{-1-}$ females.

FAAH deficiency impairs normal embryo development. We compared the in vivo developmental potential of early embryos in the presence or absence of FAAH. As shown in Table 1, we observed delayed and asynchronous development of preimplantation embryos in
$\mathrm{Faah}^{-1-}$ females when recovered from oviducts on days 2.5 and 3 of pregnancy and from both oviducts and uteri on day 4. On day 2 midnight (day 2.5), while most embryos (94\%) recovered from pregnant wild-type females were at the 4-cell stage, only about $58 \%$ of embryos from $\mathrm{Faah}^{-/-}$mice were at the 4-cell stage, with increased numbers at the 2- and 3 -cell stages (Table 1). In the morning of day 3 , about $14 \%$ and $72 \%$ of wild-type embryos recovered were at the 12- and 8-cell stages, respectively. In contrast, none of the embryos recovered from $\mathrm{Faah}^{-/-}$females were at the 12-cell stage, and only about $40 \%$ of them were at the 8 -cell stage, resulting in an increased population of 4- and 6-cell embryos (Table 1). On day 4 mornings, about $91 \%$ of wild-type embryos were blastocysts compared with only about $59 \%$ of $\mathrm{Faah}^{-/-}$embryos at the blastocyst stage; a considerable number of $\mathrm{Faah}^{-/-}$embryos were at the morula stage (Table 1 ). These morulae were apparently viable and normal and showed no sign of apoptosis by TUNEL assay (data not shown), unlike those exposed to sustained levels of THC.

Cell lineage-specific marker genes are aberrantly expressed in Faah mutant embryos. Preimplantation embryo development involves the transition of totipotent fertilized eggs to blastocysts with the

Table 1

Developmental stages of embryos on days $2.5-4$ of pregnancy

\begin{tabular}{|c|c|c|c|c|c|c|c|c|c|c|c|}
\hline \multirow{2}{*}{$\begin{array}{l}\text { Day } \\
\text { examined }\end{array}$} & \multirow[t]{2}{*}{ Genotype } & \multirow{2}{*}{$\begin{array}{l}\text { No. of mice } \\
\text { with embryos }\end{array}$} & \multirow{2}{*}{$\begin{array}{l}\text { No. of total } \\
\text { embryos }\end{array}$} & \multicolumn{8}{|c|}{ Stage of embryo development, no. (\%) } \\
\hline & & & & 2-Cell & 3-Cell & 4-Cell & 6-Cell & 8-Cell & 12-Cell & Morula & Blastocyst \\
\hline 2.5 & WT & 12 & 93 & 0 & $2(2 \%)$ & $87(94 \%)$ & $4(4 \%)$ & & & & \\
\hline & $\mathrm{Faah}^{-1}$ & 10 & 67 & $9(13 \%)$ & $18(27 \%)$ & $39(58 \%)$ & $1(2 \%)$ & & & & \\
\hline 3 & WT & 15 & 130 & & & $5(4 \%)$ & $13(10 \%)$ & $94(72 \%)$ & $18(14 \%)$ & & \\
\hline & $\mathrm{Faah}^{-1-}$ & 9 & 70 & & & $7(10 \%)$ & $35(50 \%)$ & $28(40 \%)$ & 0 & & \\
\hline 4 & WT & 36 & 334 & & & & & & 0 & $30(9 \%)$ & $304(91 \%)$ \\
\hline & $\mathrm{Faah}^{-1}$ & 29 & 253 & & & & & & $7(3 \%)$ & $97(38 \%)$ & $149(59 \%)$ \\
\hline
\end{tabular}

Wild-type or Faah ${ }^{-1-}$ embryos were recovered by flushing oviducts at midnight on day 2.5 , at 10 am on day 3 , or by flushing both oviducts and uteri at 10 am on day 4 of pregnancy. Developmental stages were determined under a stereo dissecting microscope. Mice without fertilized eggs were excluded from the experiments. 


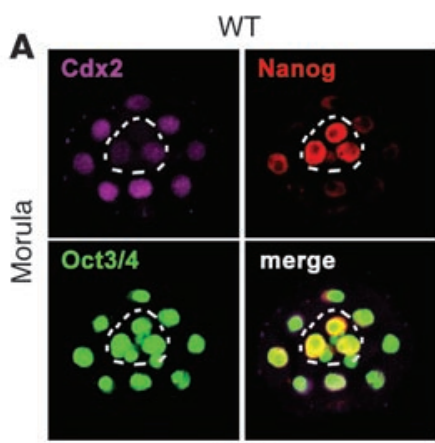

D3.5
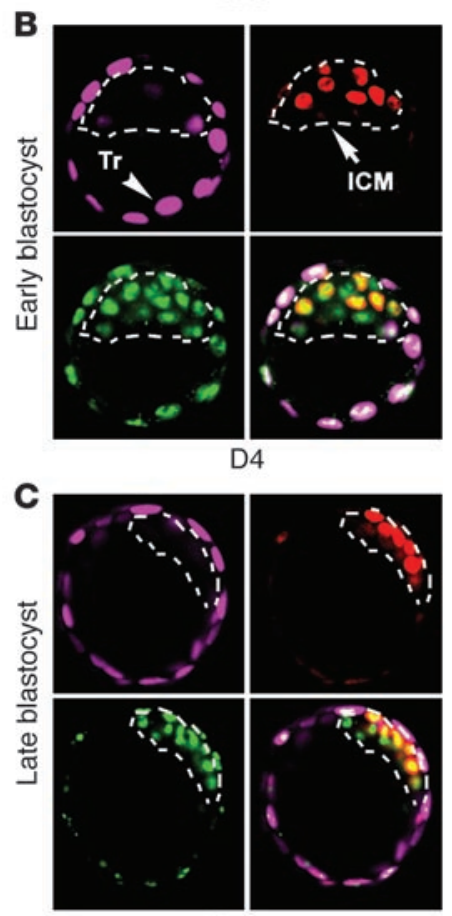

D4.25

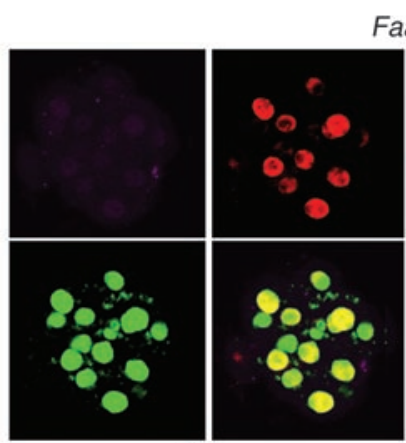

D3.5
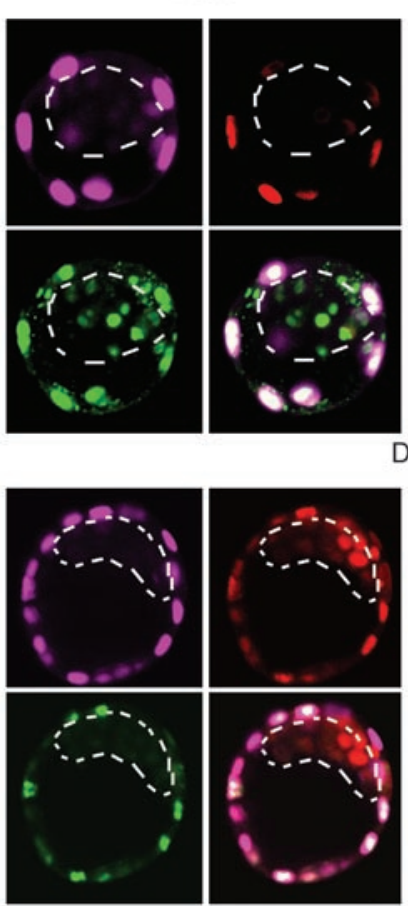

D4.25

D4
Faah $^{-1-}$

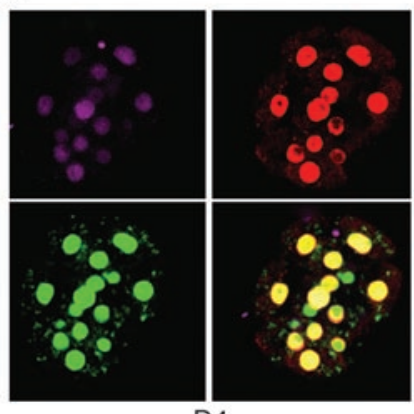

D4
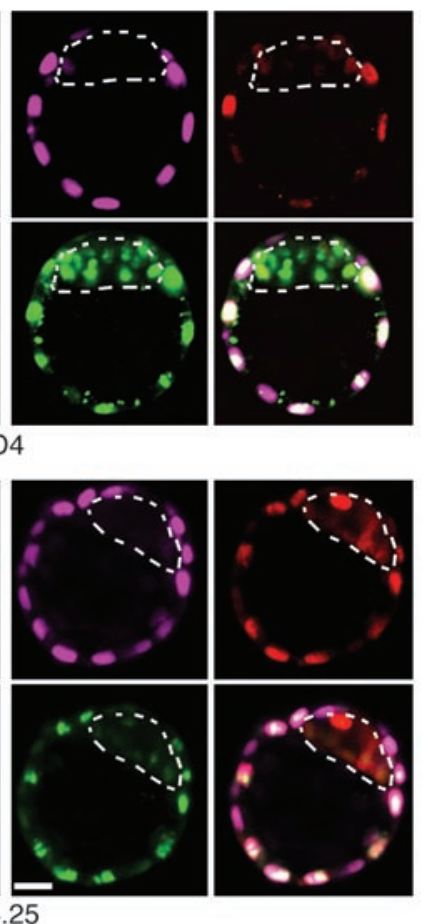

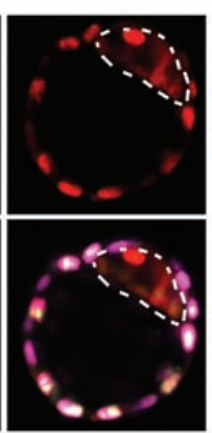

Figure 5

Expression of Cdx2, Nanog, and Oct3/4 is aberrant in Faah-deficient morulae (A) and early (B) and late blastocysts (C). Confocal immunofluorescence shows Cdx2 expression (pink) in outer cells of morulae and in Tr cells of wild-type blastocysts. In contrast, Nanog (red) was clearly detected in a subset of inner cells of morulae and primarily in the ICM of blastocysts. While Oct3/4 (green) was detected in all cells of wild-type morulae (D3.5) and early blastocysts (D4), the expression was downregulated in $\mathrm{Tr}$ cells, with sustained expression in ICM cells in late expanded blastocysts (D4.25). In contrast, the expression patterns of $\mathrm{Cdx} 2$, Nanog, and Oct3/4 in Faah $^{-/}$embryos were aberrant. Unlike in wild-type embryos, Cdx2 expression was barely detected in $\mathrm{Faah}^{-/-}$morulae, but the expression in asynchronously developing mutant morulae and blastocysts on day 4 morning was comparable to that of wild-type embryos. While the expression of Nanog and Oct3/4 was observed in most cells in $\mathrm{Faah}^{-/-}$morulae, it was selectively downregulated in ICM cells, with sustained higher levels in Tr cells in mutant blastocysts in a stage-dependent manner (scale bar: $25 \mu \mathrm{m})$. pluripotent inner cell mass (ICM) and the Tr, the progenitor of trophoblast cells. To explore the underlying cause of the defective embryo growth in the absence of FAAH, we examined the expression profiles of $\mathrm{Cdx} 2$, Nanog, and Oct $3 / 4$, known key transcription factors involved in lineage specification in early embryos (27-33). In wild-type embryos, $\mathrm{Cdx} 2$ was first detected in 8-cell embryos (data not shown), but its expression was selectively upregulated in outer cells of morulae on day 3.5 of pregnancy. In contrast, Nanog was prominently expressed in a subset of inner cells of morulae, with Oct $3 / 4$ being expressed in all cells (Figure $5 \mathrm{~A}$ ). With the transformation of morulae into early blastocysts on the morning of day $4, \mathrm{Cd} 2$ expression was substantially upregulated, with restricted localization to $\operatorname{Tr}$ cells. However, Nanog was detected primarily in ICM cells, while Oct3/4 was still detected in both cell types in early blastocysts (Figure 5B). With the progression of blastocyst expansion and maturation, Oct $3 / 4$ expression was substantially downregulated in Tr cells, with sustained high levels in ICM cells (Figure 5C). These contrasting expression profiles of Cdx2, Nanog, and Oct3/4 in late preimplantation embryos are consistent with the previous assertion that coordinated interactions of these transcription factors ensure normal lineage segregation during blastocyst formation (27-33). Therefore, we speculated that asynchronous development of Faah mutant embryos in vivo could be due to dysregulated expression of these genes. Indeed, we observed aberrant expression patterns of $\mathrm{Cdx} 2$, Nanog, and Oct3/4 in the mutant embryos. For example, unlike in wild-type embryos, $\mathrm{Cdx} 2$ expression was barely detected in many $\mathrm{Faah}^{-/-}$embryos even at the morula stage on day 3.5 , but this expression in slow-growing $\mathrm{Faah}^{-/-}$morulae and blastocysts on day 4 became comparable to that of wild-type embryos (Figure 5, A and B). Surprisingly, the expression of Nanog was not only observed in most cells in many of the Faah-null morulae (Figure 5A), its expression was conversely downregulated in ICM cells, with sustained higher levels in Tr cells in both early and late blastocysts (Figure 5, B and C). Moreover, while the expression of Oct3/4 in $\mathrm{Faah}^{-/-}$morulae and early blastocysts showed a similar pattern to that observed in wild-type embryos (Figure 5, A and B), its expression was maintained at relatively higher levels in Tr cells, with remarkable decreases in ICM cells of late blastocysts (Figure 5C). These findings provide evidence that enhanced anandamide signaling resulting from FAAH deficiency induces a deferred $\mathrm{Cd} \times 2$ expression in soon-to-be Tr cells and ectopic expressions of both Nanog and Oct $3 / 4$ in Tr cells. Collectively, 


\section{Table 2}

FAAH deficiency causes failure of on-time implantation in mice

$\begin{array}{lcccc}\text { Genotype } & \begin{array}{c}\text { No. of mice } \\ \text { examined }\end{array} & \begin{array}{c}\text { No. of mice } \\ \text { with IS (\%) }\end{array} & \begin{array}{c}\text { No. of } \\ \text { IS }\end{array} & \begin{array}{c}\text { No. of embryos } \\ \text { recovered }\end{array} \\ \text { WT } & 8 & 8(100 \%) & 7.4 \pm 0.3 & \text { N/A } \\ \text { Faah }^{-/} & 7 & 2(28 \%) & 7.0 \pm 1.0 & 24 \mathrm{~A} \\ \text { Faah }^{-/}+\text {SR141716 } & 13 & 10(77 \%) & 6.6 \pm 0.2 & 19\end{array}$

Both wild-type and $\mathrm{Faah}^{-/-}$mice mated with males of the same genotype were examined for implantation sites (IS) at midnight on day 4 of pregnancy by intravenous injection of Chicago blue dye solution. If no implantation site was noted, uteri were flushed to recover any unimplanted embryos. Mice without fertilized eggs were excluded from the experiments. Implantation failure was noted in a large portion of $\mathrm{Faah}^{-/-}$ mice and was substantially corrected by the selective CB1 antagonist SR141716. ATwenty-nine percent (7 of 24) of embryos recovered from the mice showing no IS were morulae; the rest of the embryos was blastocysts. N/A, not applicable. The values are expressed as mean \pm SEM.

the results suggest that one cause of asynchronous embryo development in the absence of FAAH is aberrant expression of these lineage-specific genes.

FAAH deficiency impairs on-time implantation, leading to subfertility. Observations of asynchronous development of early embryos with aberrant gene expression and their impaired oviductal transport into uteri of $\mathrm{Faah}^{-/}$mice led us to speculate that loss of FAAH defers the normal window of implantation. Thus, we compared the status of implantation in the wild-type and mutant mice. In mice, the initiation of embryo attachment with the uterine luminal epithelium occurs on day 4.5 of pregnancy (34). We observed that all wild-type mice ( 8 of 8 ) examined on day 4.5 showed an average of 7.4 implantation sites per mouse, whereas only 2 of 7 (28\%) $\mathrm{Faah}^{-/-}$ mice showed implantation (Table 2). A considerable number of unimplanted embryos were recovered from those mutant females without any sign of implantation (blue bands), and 29\% of recovered embryos were at the morula stage (Table 2), further providing evidence for asynchronous embryo development in the absence of FAAH. However, it seems that these slow-growing embryos eventually form blastocysts and implant beyond the normal window of implantation, since an increased number of $\mathrm{Faah}^{-/}$females showed implantation on day 5 mid-morning, but with much reduced endometrial vascular permeability (data not shown). This deferred ontime implantation in Faah-null females was substantially corrected by the selective CB1 antagonist SR141716 (Table 2), suggesting that enhanced anandamide/CB1 signaling derails the preimplantation processes, thus shifting the window of implantation.
Recent evidence points toward a new concept that a short delay in on-time implantation leads to poor pregnancy outcome (35-38). Our finding of a deferred window of implantation due to the loss of FAAH provoked us to further address whether these impaired preimplantation events in $\mathrm{Faah}^{-/-}$females impact the success of term pregnancy. As shown in Table 3, compromised pregnancy outcome with reduced litter size was frequently observed in plug-positive $\mathrm{Faah}^{-/-}$mice mated with either $\mathrm{Faah}^{-/-}$or wild-type males. Moreover, the birth weights of mutant offspring were significantly lower when compared with those of wildtype pups or pups born to mutant mothers mated with wild-type males. This restricted in utero fetal growth in Faab-null females may partially account for lower BWs of adult $\mathrm{Faah}^{-/-}$mice (8-week-old) compared with wild-type mice at similar ages (female: $20.3 \pm 0.3$ g versus $22.4 \pm 0.4$ g; male: $25.4 \pm 0.5$ g versus $27.6 \pm 0.5 \mathrm{~g}$ ). In addition, it was also noted that pregnant $\mathrm{Faah}^{-/-}$females had parturition 8-12 hours earlier than wild-type females (Table 3), although determining the cause of this will require further investigation. Nonetheless, the high incidence of compromised pregnancy with reduced litter size and preterm labor in Faab-null females are clinically relevant, since reduced peripheral FAAH activity is associated with spontaneous abortion in women $(39,40)$.

\section{Discussion}

The efficacy of the endocannabinoid system is regulated at different levels, according to: the status of the cannabinoid receptors as well as the levels of endocannabinoid ligands that depend on their synthesis, uptake, and breakdown. We provide here genetic, molecular, pharmacological, and physiological evidence that the degrading enzyme FAAH is a key regulator of anandamide signaling, which directs various preimplantation events, prerequisites for successful pregnancy outcome. We also show that both embryos and oviducts are endowed with the machinery to regulate local anandamide levels conducive to preimplantation processes. While our previous studies have shown a critical role of CB1 during early pregnancy, the present study reveals that a tight regulation of anandamide levels to produce an optimal endocannabinoid tone is as critical as the receptor in directing preimplantation processes. That the endocannabinoid system has key roles during pregnancy is clearly evident from our observations of compromised implantation events resulting from alterations in CB1 function or anandamide status.

\section{Table 3}

FAAH deficiency frequently leads to pregnancy failure in mice

\begin{tabular}{|c|c|c|c|c|c|}
\hline Genotype & $\begin{array}{l}\text { No. of plug- } \\
\text { positive mice }\end{array}$ & $\begin{array}{l}\text { No. of mice with } \\
\text { term pregnancy (\%) }\end{array}$ & $\begin{array}{l}\text { Gestation } \\
\text { length (d) }\end{array}$ & Litter size & $\begin{array}{l}\text { Fetal birth } \\
\text { wt (mg) }\end{array}$ \\
\hline WT (female) $\times$ WT (male) & 63 & $60(95 \%)$ & $20.1 \pm 0.1$ & $8.2 \pm 0.2$ & $1,577 \pm 22$ \\
\hline $\mathrm{Faah}^{-1-}($ female $) \times \mathrm{Faah}^{-/-}$(male) & 76 & $50(66 \%)$ & $19.7 \pm 0.1^{\mathrm{A}}$ & $4.5 \pm 0.3^{A}$ & $1,447 \pm 20^{A}$ \\
\hline Faah $^{-1-}($ female $) \times$ WT (male $)$ & 49 & $39(80 \%)$ & $19.6 \pm 0.1^{\mathrm{A}}$ & $6.0 \pm 0.2^{A}$ & $1,540 \pm 36^{B}$ \\
\hline
\end{tabular}

Plug-positive wild-type or $\mathrm{Faah}^{-/}$female mice mated with wild-type or Faah mutant males were observed for delivery of pups at term, and the gestation period, litter size, and fetal birth weight were recorded. Compromised pregnancy with reduced litter size was noted in a considerable number of $F a a h^{-/-}$females when mated with either $\mathrm{Faah}^{-/}$or wild-type males. The birth weights of mutant pups were also significantly lower when compared with those of wild-type pups or pups born to mutant mothers mated with wild-type males. In addition, Faah ${ }^{-1-}$ females had parturition $8-12$ hours earlier than wild-type females. Statistical analysis was performed by unpaired 1-tailed Student's $t$ test (mean $\pm \mathrm{SEM}$ ). ${ }^{\mathrm{A} P}<0.005$ compared with wild-type. ${ }^{\mathrm{B} P}<0.05$ compared with Faah-null mice. 
Increasing evidence suggests that anandamide synthesis via NAPE-PLD and its release from cells occur only when and where it is needed in vivo (41). This on-demand nature of anandamide signaling under physiological conditions largely depends on its rapid clearance by intracellular FAAH $(13,42)$. Our observation of stage- and region-specific contrasting expression profiles of Napepld and Faab in the oviduct suggests that anandamide synthesis and degradation occur in an on-demand manner to create appropriate signaling for normal fertilization in the oviduct ampulla with lower anandamide levels and then for timely transport of developing embryos through the isthmus into the uterine lumen with relatively higher anandamide levels. There is evidence that a gradient of anandamide signaling in the fallopian tube is physiologically relevant to normal sperm function required for fertilization in humans (43). This is consistent with the observation that sperm cells express CB1, NAPE-PLD, and FAAH (44-47). It is not yet clear whether anandamide signaling machinery is present in the cumulus-oocyte complex; our preliminary results in mice show that this complex expresses NAPE-PLD but not CB1 (data not shown). However, the role of anandamide originating from this complex in modulating sperm function and fertilization cannot be ruled out.

The on-demand model of anandamide signaling in early pregnancy is supported by the findings of asynchronous development of preimplantation embryos and their impeded oviductal transport upon genetic or pharmacological silencing of FAAH function. These defects were primarily due to enhanced anandamide signaling via CB1, but not other FAAH-sensitive amides, since treatment with a selective CB1 antagonist largely restored the normal preimplantation events. Aberrant expression of cell lineage-specific genes $\mathrm{Cdx} 2$, Nanog, and Oct3/4 in Faah mutant embryos suggests that asynchronous and impeded growth occurs due to defective and/or delayed cell lineage specification. The observation of aberrant cell lineage-specific gene expression in developmentally asynchronous embryos with locally elevated anandamide levels in oviducts of $\mathrm{Faah}^{-/-}$mice is significant and suggests that endocannabinoid signaling has a role in cell lineage specification during early development. However, this aberrant gene expression does not appear to be totally detrimental to subsequent development, since many Faah mutant embryos develop to term fetuses, albeit at a compromised frequency.

Our present findings have high clinical importance, since embryo retention in the fallopian tube is a significant cause of ectopic pregnancy in women, the incidence of which has markedly increased during the past decade (48). In addition, our observation of similar defects of preimplantation events and pregnancy failure in mice exposed to excessive THC raises concern that the adverse effects of maternal use of marijuana on offspring could be seeded very early in pregnancy.

Our present investigation presents what we believe to be novel information: that FAAH serves as a metabolic gatekeeper for the regulation of on-site anandamide levels in order to maintain an in vivo endocannabinoid tone conducive to normal development of preimplantation embryos and their on-time homing into uterus. The evidence that anandamide is beneficial to alleviating pain, cancer, neurodegeneration, and anxiety has heightened interest and efforts to develop FAAH inhibitors as novel therapeutic agents for treating these conditions $(25,49-51)$. However, our findings raise the issue of the risk involved in interfering with FAAH function in terms of female fertility, especially in women of reproductive age, versus its benefits in treating pathological disorders. In fact, downregulation of FAAH function in peripheral lymphocytes is associated with early pregnancy loss in women $(39,40)$. There is now evidence that a single nucleotide polymorphism in the human FAAH gene leads to reduced FAAH expression and activity in lymphocytes (52) and is strongly associated with problem drug use (53). It remains to be seen whether the incidence of early reproductive disorders, such as ectopic pregnancy and miscarriages, is associated with $F A A H$ gene polymorphism or mutation in humans. Since variations in anandamide and CB1 functions are observed in mice on different genetic backgrounds $(54,55)$, it is hoped that future studies will determine whether our present findings in Faah mutant mice on the C57BL/6J background are sustained or altered in mice with different genetic makeup.

\section{Methods}

Animals. Faah-deficient mice on a C57BL/6J genetic background were generated as previously described (42). Adult wild-type and $\mathrm{Faah}^{-/}$mice were housed at Vanderbilt University Animal Care Facility according to NIH and institutional guidelines for laboratory animals. The animal protocol was approved by the Vanderbilt Institutional Animal Care and Use Committee. PCR analysis of tail genomic DNA determined the genotypes. The postnatal growth patterns of Faah-null and wild-type mice appeared to be comparable, although the BWs of null offspring at birth or at the age of 8 weeks were lower than those of wild-type mice at similar ages. Females were mated with fertile males of the same strain to induce pregnancy; the day that the vaginal plug was first observed was considered day 1 of pregnancy. Preimplantation embryos at the 1-cell, 2-cell, 4-cell, 8-cell, morula, and blastocyst stages were collected by flushing the oviduct and uterus as appropriate. Embryos at these stages were pooled from several mice and were stored in a small volume of PBS at $-80^{\circ} \mathrm{C}$ until used for RT-PCR or fixed in $4 \%$ paraformaldehyde in $0.1 \mathrm{M}$ PBS ( $\mathrm{pH}$ 7.4) for immunofluorescence staining. Oviducts on days 1-4 of pregnancy were processed for anandamide measurement and in situ hybridization.

In vivo delivery of drugs. THC, CBD, and CBN were obtained from National Institute on Drug Abuse. These drugs were dissolved in propylene glycol and delivered at a constant rate via miniosmotic pumps (ALZET; DURET Corp.) to study their effects on embryo development, oviductal transport, and implantation in wild-type mice. Pumps loaded with each drug were placed subcutaneously under the back skin in plug-positive wild-type mice on day 1 afternoon, and delivery continued until sacrifice. The daily dose of each drug was calculated to be $5 \mathrm{mg} / \mathrm{kg}$ BW. This dose was chosen based on earlier studies (56-58) and our initial results. To prevent rapid metabolism of infused drugs by cytochrome $\mathrm{P} 450$ enzymes, experimental mice receiving the cannabis compounds were injected twice daily with 0.1 $\mathrm{ml}$ of clotrimazole in sesame oil $(12.5 \mathrm{mg} / \mathrm{kg} \mathrm{BW})$. The control group of mice (vehicle-treated) received a similar treatment of clotrimazole. Another group of plug-positive wild-type mice received subcutaneous injection of URB597 (a selective FAAH inhibitor) dissolved in triolein/ethanol (4:1) at a dose of $1 \mathrm{mg} / \mathrm{kg} \mathrm{BW}$ on days $1-3$. The control group of mice received the same vehicle. To determine whether the effects are mediated by CB1, wildtype females were treated with SR141716 (a selective CB1 antagonist) at a concentration of $4 \mathrm{mg} / \mathrm{kg} \mathrm{BW}$ on days 1-3 along with THC or URB597. Faah-null females also received a similar treatment of SR141716 to examine the effects of compromised CB1 signaling. Mice were sacrificed on days 4-5 of pregnancy. On day 4 morning, oviducts and uterine horns were separately flushed with Whitten's medium to recover embryos. The stage of development and morphological appearance of embryos were determined under a dissecting microscope. Embryos were subjected to TUNEL assay to determine the apoptosis status. Implantation sites on days 4.5 and 5 were determined by an intravenous injection of $0.1 \mathrm{ml}$ of $1 \%$ Chicago blue $\mathrm{B}$ 
dye solution. Uteri without implantation sites were flushed with Whitten's medium to recover embryos. Mice without fertilized eggs were excluded from the experiments.

Analysis of anandamide. Oviduct specimens (50-60 mg) were pooled separately from 10-15 pregnant wild-type or $\mathrm{Faah}^{-/}$mice in each group $(n=3-6)$ and were assayed for anandamide as previously described (8).

In situ hybridization. Frozen sections $(10 \mu \mathrm{m})$ were hybridized with ${ }^{35} \mathrm{~S}$-labeled cRNA probes for mouse Nape-pld or Faab as described previously (34). Sections hybridized with sense probes served as negative controls and showed no positive signals.

RT-PCR analysis of Nape-pld and Faah mRNAs. Nape-pld and Faab mRNAs in the preimplantation embryos of different development stages was analyzed by RT-PCR followed by Southern hybridization as described previously (7). In brief, total RNAs from mouse brain and 100 mouse embryos at each stage were isolated using TRIzol Reagent (Invitrogen). One microgram total RNA from brain or $25 \%$ of the embryonic RNA was reverse-transcribed using respective antisense primers for Nape-pld or Faab genes and then subjected to PCR reaction. The amplified product was electrophoresed on agarose gels (1.5\%), blotted, and analyzed by Southern hybridization. Experimental and control groups were analyzed simultaneously.

Immunofluorescence staining. To localize NAPE-PLD, FAAH, Oct3/4, Nanog, and $\mathrm{Cdx} 2$ in embryos at different stages of development, immunofluorescence images were captured in a Zeiss LSM 510 confocal scanning laser microscope as described previously (10). Antibodies specific to NAPE-PLD $(0.5 \mu \mathrm{g} / \mathrm{ml}$; Cayman Chemical), FAAH $(0.5 \mu \mathrm{g} / \mathrm{ml}$; custom made), Oct3/4 (1 $\mu \mathrm{g} / \mathrm{ml}$; Abcam), Nanog (1 $\mu \mathrm{g} / \mathrm{ml} ; \mathrm{R} \& D$ Systems), and $\mathrm{Cd} \times 2(1 \mu \mathrm{g} / \mathrm{ml}$; BioGenex) and secondary antibodies conjugated with FITC, TRITC, or Cy5 dyes (Jackson ImmunoResearch Laboratories Inc.) were used to detect immunofluorescence signaling. SYTO13 green fluorescence dye (Invitrogen) was used for nuclear staining.
Apoptosis assays. The apoptosis status in preimplantation embryos after exposure to THC was examined with a TUNEL procedure according to the manufacturer's protocol (Upstate USA Inc.). In brief, after fixing in $4 \%$ paraformaldehyde in $0.1 \mathrm{M}$ PBS ( $\mathrm{pH}$ 7.4), embryos were treated with $0.1 \%$ Tween-20/PBS solution and incubated with a reaction mixture containing biotin-dUTP and terminal deoxynucleotidyl transferase for 60 minutes. Fluorescein-conjugated avidin was applied to the sample, which was then incubated in the dark for 30 minutes. After washing, embryos were counterstained with propidium iodide. The apoptosis signals were visualized and photographed in a Zeiss LSM 510 confocal scanning laser microscope as described previously (10).

\section{Acknowledgments}

This work was supported in part by NIH grants DA06668, HD12304, and HD33994 to S.K. Dey and ES07814 and HD37830 to S.K. Das. S.K. Dey is a recipient of Method to Extend Research in Time (MERIT) Awards from the National Institute on Drug Abuse (NIDA) and the National Institute of Child Health and Human Development (NICHD). H. Wang is a recipient of the Solvay-Mortola Research Award from the Society for Gynecologic Investigation. H. Xie is a Lalor Foundation postdoctoral fellow.

Received for publication March 22, 2006, and accepted in revised form May 23, 2006.

Address correspondence to: Sudhansu K. Dey, Departments of Pediatrics, Cell and Developmental Biology, and Pharmacology, Division of Reproductive and Developmental Biology, Vanderbilt University Medical Center, Nashville, Tennessee 37232, USA. Phone: (615) 3228642; Fax: (615) 322-4704; E-mail: sk.dey@vanderbilt.edu.
1. Farquhar, C.M. 2005. Ectopic pregnancy. Lancet. 366:583-591.

2. Devane, W.A., et al. 1992. Isolation and structure of a brain constituent that binds to the cannabinoid receptor. Science. 258:1946-1949.

3. Mechoulam, R., et al. 1995. Identification of an endogenous 2-monoglyceride, present in canine gut, that binds to cannabinoid receptors. Biochem. Pharmacol. 50:83-90.

4. Sugiura, T., et al. 1995. 2-Arachidonoylglycerol: a possible endogenous cannabinoid receptor ligand in brain. Biochem. Biophys. Res. Commun. 215:89-97.

5. Matsuda, L.A., Lolait, S.J., Brownstein, M.J., Young, A.C., and Bonner, T.I. 1990. Structure of a cannabinoid receptor and functional expression of the cloned cDNA. Nature. 346:561-564.

6. Munro, S., Thomas, K.L., and Abu-Shaar, M. 1993. Molecular characterization of a peripheral receptor for cannabinoids. Nature. 365:61-65.

7. Paria, B.C., Das, S.K., and Dey, S.K. 1995. The preimplantation mouse embryo is a target for cannabinoid ligand-receptor signaling. Proc. Natl. Acad. Sci.U. S. A. 92:9460-9464.

8. Wang, H., et al. 2004. Aberrant cannabinoid signaling impairs oviductal transport of embryos. Nat. Med. 10:1074-1080.

9. Paria, B.C., et al. 2001. Dysregulated cannabinoid signaling disrupts uterine receptivity for embryo implantation. J. Biol. Chem. 276:20523-20528.

10. Wang, H., et al. 2003. Differential G proteincoupled cannabinoid receptor signaling by anandamide directs blastocyst activation for implantation. Proc. Natl. Acad. Sci. U. S. A. 100:14914-14919.

11. Di Marzo, V., et al. 1994. Formation and inactivation of endogenous cannabinoid anandamide in central neurons. Nature. 372:686-691.

12. Okamoto, Y., Morishita, J., Tsuboi, K., Tonai, T. and Ueda, N. 2004. Molecular characterization of a phospholipase D generating anandamide and its congeners. J. Biol. Chem. 279:5298-5305.

13. Cravatt, B.F., et al. 1996. Molecular characterization of an enzyme that degrades neuromodulatory fatty-acid amides. Nature. 384:83-87.

14. Compton, W.M., Grant, B.F., Colliver, J.D., Glantz, M.D., and Stinson, F.S. 2004. Prevalence of marijuana use disorders in the United States: 1991-1992 and 2001-2002. JAMA. 291:2114-2121.

15. Hall, W., and Solowij, N. 1998. Adverse effects of cannabis. Lancet. 352:1611-1616.

16. Feng, T. 1993. Substance abuse in pregnancy. Curr. Opin. Obstet. Gynecol. 5:16-23.

17. Gaoni, Y., and Mechoulam, R. 1964. Isolation, structure, and partial synthesis of an active constituent of hashish. J. Am. Chem. Soc. 86:1646-1647.

18. Bisogno, T., et al. 2001. Molecular targets for cannabidiol and its synthetic analogues: effect on vanilloid VR1 receptors and on the cellular uptake and enzymatic hydrolysis of anandamide. Br. J. Pharmacol. 134:845-852.

19. Hanus, L.O., et al. 2005. Enantiomeric cannabidiol derivatives: synthesis and binding to cannabinoid receptors. Org. Biomol. Chem. 3:1116-1123.

20. Lagu, S.G., Varona, A., Chambers, J.D., and Reggio, P.H. 1995. Construction of a steric map of the binding pocket for cannabinoids at the cannabinoid receptor. Drug Des. Discov. 12:179-192.

21. Psychoyos, A. 1973. Endocrine control of egg implantation. In Handbook of physiology. R.O. Greep and E.B. Astwood, editors. American Physiological Society. Washington, DC, USA. 187-215.

22. Paria, B.C., Huet-Hudson, Y.M., and Dey, S.K. 1993. Blastocyst's state of activity determines the "window" of implantation in the receptive mouse uterus. Proc. Natl. Acad. Sci. U. S. A. 90:10159-10162.

23. Wang, J., Paria, B.C., Dey, S.K., and Armant, D.R. 1999. Stage-specific excitation of cannabinoid receptor exhibits differential effects on mouse embryonic development. Biol. Reprod. 60:839-844.

24. Guo, Y., et al. 2005. N-acylphosphatidylethanolamine-hydrolyzing phospholipase D is an important determinant of uterine anandamide levels during implantation. J. Biol. Chem. 280:23429-23432.

25. Kathuria, S., et al. 2003. Modulation of anxiety through blockade of anandamide hydrolysis. Nat. Med. 9:76-81.

26. Cravatt, B.F., and Lichtman, A.H. 2002. The enzymatic inactivation of the fatty acid amide class of signaling lipids. Chem. Phys. Lipids. 121:135-148.

27. Strumpf, D., et al. 2005. Cdx2 is required for correct cell fate specification and differentiation of trophectoderm in the mouse blastocyst. Development. 132:2093-2102.

28. Niwa, H., et al. 2005. Interaction between Oct3/4 and $\mathrm{Cd} 2$ determines trophectoderm differentiation. Cell. 123:917-929.

29. Meissner, A., and Jaenisch, R. 2006. Generation of nuclear transfer-derived pluripotent ES cells from cloned Cdx2-deficient blastocysts. Nature. 439:212-215.

30. Mitsui, K., et al. 2003. The homeoprotein Nanog is required for maintenance of pluripotency in mouse epiblast and ES cells. Cell. 113:631-642.

31. Chambers, I., et al. 2003. Functional expression cloning of Nanog, a pluripotency sustaining factor in embryonic stem cells. Cell. 113:643-655.

32. Nichols, J., et al. 1998. Formation of pluripotent stem cells in the mammalian embryo depends on the POU transcription factor Oct4. Cell. 95:379-391.

33. Niwa, H., Miyazaki, J., and Smith, A.G. 2000. Quantitative expression of Oct-3/4 defines differentiation, dedifferentiation or self-renewal of ES cells. Nat. Genet. 24:372-376.

34. Das, S.K., et al. 1994. Heparin-binding EGF-like growth factor gene is induced in the mouse uterus 
temporally by the blastocyst solely at the site of its apposition: a possible ligand for interaction with blastocyst EGF-receptor in implantation. Development. 120:1071-1083.

35. Wang, H., and Dey, S.K. 2006. Roadmap to embryo implantation: clues from mouse models. Nat. Rev. Genet. 7:185-199.

36. Song, H., et al. 2002. Cytosolic phospholipase A2alpha is crucial for 'on-time' embryo implantation that directs subsequent development. Development. 129:2879-2889.

37. Ye, X., et al. 2005. LPA3-mediated lysophosphatidic acid signalling in embryo implantation and spacing. Nature. 435:104-108.

38. Wilcox, A.J., Baird, D.D., and Weinberg, C.R. 1999. Time of implantation of the conceptus and loss of pregnancy. N. Engl. J. Med. 340:1796-1799.

39. Maccarrone, M., et al. 2002. Low fatty acid amide hydrolase and high anandamide levels are associated with failure to achieve an ongoing pregnancy after IVF and embryo transfer. Mol. Hum. Reprod. 8:188-195.

40. Maccarrone, M., et al. 2000. Relation between decreased anandamide hydrolase concentrations in human lymphocytes and miscarriage. Lancet. 355:1326-1329.

41. Di Marzo, V., Bifulco, M., and De Petrocellis, L. 2004. The endocannabinoid system and its therapeutic exploitation. Nat. Rev. Drug Discov. 3:771-784.

42. Cravatt, B.F., et al. 2001. Supersensitivity to anandamide and enhanced endogenous cannabinoid signaling in mice lacking fatty acid amide hydro- lase. Proc. Natl. Acad. Sci. U. S. A. 98:9371-9376.

43. Schuel, H., et al. 2002. Evidence that anandamidesignaling regulates human sperm functions required for fertilization. Mol. Reprod. Dev. 63:376-387.

44. Schuel, H., and Burkman, L.J. 2005. A tale of two cells: endocannabinoid-signaling regulates functions of neurons and sperm. Biol. Reprod. 73:1078-1086.

45. Maccarrone, M., et al. 2005. Characterization of the endocannabinoid system in boar spermatozoa and implications for sperm capacitation and acrosome reaction. J. Cell Sci. 118:4393-4404.

46. Rossato, M., Ion Popa, F., Ferigo, M., Clari, G., and Foresta, C. 2005. Human sperm express cannabinoid receptor $\mathrm{Cb} 1$, the activation of which inhibits motility, acrosome reaction, and mitochondrial function. J. Clin. Endocrinol. Metab. 90:984-991.

47. Cobellis, G., et al. 2006. Endocannabinoid system in frog and rodent testis: type-1 cannabinoid receptor and fatty acid amide hydrolase activity in male germ cells. Biol. Reprod. doi:10.1095/biolreprod. 106.051730 .

48. Centers for Disease Control and Prevention. 1995. Ectopic pregnancy - United States, 1990-1992. MMWR Morb. Mortal. Wkly. Rep. 44:46-48.

49. Lichtman, A.H., Shelton, C.C., Advani, T., and Cravatt, B.F. 2004. Mice lacking fatty acid amide hydrolase exhibit a cannabinoid receptor-mediated phenotypic hypoalgesia. Pain. 109:319-327.

50. Bifulco, M., and Di Marzo, V. 2002. Targeting the endocannabinoid system in cancer therapy: a call for further research. Nat. Med. 8:547-550.

51. Guzman, M. 2003. Cannabinoids: potential anti- cancer agents. Nat. Rev. Cancer. 3:745-755.

52. Chiang, K.P., Gerber, A.L., Sipe, J.C., and Cravatt, B.F. 2004. Reduced cellular expression and activity of the P129T mutant of human fatty acid amide hydrolase: evidence for a link between defects in the endocannabinoid system and problem drug use. Hum. Mol. Genet. 13:2113-2119.

53. Sipe, J.C., Chiang, K., Gerber, A.L., Beutler, E., and Cravatt, B.F. 2002. A missense mutation in human fatty acid amide hydrolase associated with problem drug use. Proc. Natl. Acad. Sci. U. S. A. 99:8394-8399.

54. Castellano, C., Ventura, R., Cabib, S., and PuglisiAllegra, S. 1999. Strain-dependent effects of anandamide on memory consolidation in mice are antagonized by naltrexone. Behav. Pharmacol. 10:453-457.

55. Hoffman, A.F., Macgill, A.M., Smith, D., Oz, M., and Lupica, C.R. 2005. Species and strain differences in the expression of a novel glutamate-modulating cannabinoid receptor in the rodent hippocampus. Eur. J. Neurosci. 22:2387-2391.

56. Shinohara, O., Henrich, R.T., and Morishima, A. 1983. Effects of chronic administration of delta9-tetrahydrocannabinol on early embryogenesis of the mouse. Biol. Reprod. 29:663-670.

57. Paria, B.C., Kapur, S., and Dey, S.K. 1992. Effects of 9-ene-tetrahydrocannabinol on uterine estrogenicity in the mouse. J. Steroid Biochem. Mol. Biol. 42:713-719.

58. Paria, B.C., et al. 1998. Effects of cannabinoids on preimplantation mouse embryo development and implantation are mediated by brain-type cannabinoid receptors. Biol. Reprod. 58:1490-1495. 